\title{
Comment
}

\section{Evolution and creation in the arena of scientific communication}

\author{
Telmo Pievani
}

The debate on Darwin's theory of evolution is a unique case for observing some particular ways in which science is perceived and experienced in society. It is a dispute which is really not very scientific at all, since it ultimately derives from the attempt to discredit a corroborated scientific explanation (and to limit its teaching) by fundamentalist fringe groups of religious and political movements of various extraction. However, it is undeniable that the clash between creationists and evolutionists must also involve, in a critical and self-reflective way, the communicative weaknesses of science and its inability to assert itself as a widespread and fully shared culture, as was also stressed by the Nature magazine in April 2005. With an international viewpoint, ranging from the United States to Europe, from Australia to Italy, in this dossier we try to make a summary investigation of the current state of the debate, with a particularly attentive eye on the communicative strategies that contend in the two fields. The well-known evolutionist and palaeolontologist of the American Museum of Natural History in New York, Niles Eldredge, comments on the great emphasis given by the New York Times in April 2006 to two important items of news concerning evolution, though it allowed itself to be drawn towards a strange form of "fair play" when, in the second article, it left the last word to the vehement criticisms of the neocreationists who support Intelligent Design. In later publications, three scientific editors of Pikaia, the Italian portal on evolution, illustrate the different developments of new creationism and the reactions of the scientific community in North America, in Australia, in Turkey and in European countries, without of course forgetting to strike a balance of the bizarre situation in Italy, where all references to the theory of evolution were removed from the middle schools syllabus in 2004. In conclusion, the authoritative biologist of Italian origin, Massimo Pigliucci, a supporter of evolutionism now on the staff of the Stony Brook University in New York, calls for a critical examination of the battle between evolutionists and creationists which would allow us to escape from the doldrums of a contrast that risks creating an even greater gulf between science and society. Particularly significant, in our opinion, was his appeal not to confuse the naturalism of scientific method with metaphysical naturalism which belongs to our philosophical choices and conscience, and to avoid false reasonings which, from the study of natural reality, deduce simplistic ethical consequences. Two promising, though steep paths which could enable the public of non specialists to understand how science is not necessarily an enemy of religion. The debate continues, with the awareness that science - in its continuous, necessary, though often insufficient self-rethinking - cannot however accept to be censures and humiliated by choices based on reasons rooted in the imposition of dogma.

\section{Acknowledgements}

Particular thanks to Carla Castellacci for her support in the realisation of this dossier.

Translated by Quickline

\begin{abstract}
Author
Telmo Pievani works as Associate Professor of Science Philosophy at the Department of Human Sciences, University of Milan - Bicocca (Italy). He is the coordinator of the Scientific Council of the Science Festival in Genoa and the Director of "Pikaia - the evolution portal". He is the author of "Homo sapiens and Other Catastrophes" An Archaeology of Globalization, Meltemi Editore, Rome, preface by
\end{abstract}


Niles Eldredge; "Introduction to Philosophy of Biology" (Italian Edition: Laterza, Roma-Bari, 2005); "La teoria dell'evoluzione. Attualità di una rivoluzione scientifica" (Il Mulino, Bologna, 2006). 